\title{
Radiofrequency Heating of the Cornea: An Engineering Review of Electrodes and Applicators
}

\author{
Enrique J. Berjano*, ${ }^{*}$, Enrique Navarro ${ }^{2}$, Vicente Ribera ${ }^{2}$, Javier Gorris $^{2}$ and Jorge L. Alión 3,4 \\ ${ }^{1}$ Institute for Research and Innovation on Bioengineering, Technical University of Valencia, Valencia, Spain \\ ${ }^{2}$ Neptury Technologies, Almassora, Spain \\ ${ }^{3}$ Cornea and Refractive Surgery Department, Vissum-Instituto Oftalmológico de Alicante, Alicante, Spain \\ ${ }^{4}$ Pathology and Surgery Department, Universidad Miguel Hernández, Elche, Spain
}

\begin{abstract}
This paper reviews the different applicators and electrodes employed to create localized heating in the cornea by means of the application of radiofrequency (RF) currents. Thermokeratoplasty (TKP) is probably the best known of these techniques and is based on the principle that heating corneal tissue (particularly the central part of the corneal tissue, i.e. the central stroma) causes collagen to shrink, and hence changes the corneal curvature. Firstly, we point out that TKP techniques are a complex challenge from the engineering point of view, due to the fact that it is necessary to create very localized heating in a precise location (central stroma), within a narrow temperature range (from 58 to $76^{\circ} \mathrm{C}$ ). Secondly, we describe the different applicator designs (i.e. RF electrodes) proposed and tested to date. This review is planned from a technical point of view, i.e. the technical developments are classified and described taking into consideration technical criteria, such as energy delivery mode (monopolar versus bipolar), thermal conditions (dry versus cooled electrodes), lesion pattern (focal versus circular lesions), and application placement (surface versus intrastromal).
\end{abstract}

\section{INTRODUCTION}

Localized heating of the cornea has been employed since 1889 for different therapeutic and surgical objectives. The best known of these techniques is probably thermokeratoplasty (TKP), which is based on the principle that heating corneal tissue (particularly the central part of the corneal tissue, i.e. the central stroma) causes collagen to shrink, and hence changes the corneal curvature [1]. However, the process can be used for other therapeutic objectives. TKP is a complex challenge from the engineering point of view (see Fig. 1). On one hand, it is necessary to create very localized heating in a precise location (central stroma), keeping the endothelium thermally protected (which is located no more than $300 \mu \mathrm{m}$ distant from the central stroma). The endothelium is a mono-cellular layer in the human eye which is non regenerable, and hence the temperature at this point should always be maintained at a safe level (e.g. lower than $45^{\circ} \mathrm{C}$ ). Consequently, the procedure requires an extremely high spatial resolution. The temperature at the epithelium is not so critical: some TKP techniques combine surface cooling to create a temperature profile with a low temperature at the epithelium (see solid line in Fig. 1). In contrast, other techniques (like intrastromal applicators) heat both the epithelium and the central stroma (see dashed line in Fig. 1).

It is known that collagen shrinkage occurs at temperatures ranging from 58 to $76^{\circ} \mathrm{C}$. However, higher thermal levels, $79^{\circ} \mathrm{C}$ or over, definitely lead to relaxation of the collagen and complete loss of its elasticity, inducing important keratocyte proliferation and accelerating collagen turnover (i.e. provoking a regression of the corrected refractive error) [2].

*Address correspondence to this author at the Institute for Research and Innovation on Bioengineering, Technical University of Valencia, Valencia, Spain; E-mail: eberjano@eln.upv.es
Therefore, the procedure also requires high resolution of the temperature reached at the target point (see Fig. 1).

In order to create corneal heating, different kinds of energy sources have been tested, such as simple thermal conduction from pre-heated probes, known as thermokeratophores [3,4], microwaves [5-7], laser [2] and ultrasound [8-10], and radiofrequency (RF) currents. However, our interest is focused on techniques for corneal heating by means of RF currents $(\approx 500 \mathrm{kHz})$, therefore in this review we describe the different designs of applicators (i.e. RF electrodes) proposed and tested to date. This review is planned from a technical point of view, i.e. the technical developments are classified and described taking into consideration technical criteria, such as energy delivery mode (monopolar versus bipolar), thermal conditions (dry versus cooled electrodes), lesion pattern (focal versus circular lesions), and application placement (surface versus intrastromal). Consequently, the developments are not necessarily related to either clinical procedures or trademarks.

\section{APPLICATORS WITH SURFACE COOLING}

The first applicator designed for applying RF currents in the human cornea was described by Doss and Albillar [11] in 1980. Since it was developed at Los Alamos Scientific Laboratory (NM, USA), the device was named the Los Alamos Keratoplasty probe [1]. However, Doss and Albillar called it the circulating saline electrode (CSE), since, while the active electrode delivered RF currents (1.6 MHz) a flow of isotonic saline (at $37^{\circ} \mathrm{C}$ ) was infused over the cornea surface [11,12] (see Fig. 2B).

The basic idea of the CSE was to improve the temperature profile obtained by the thermokeratophore during thermokeratoplasty (TKP). The thermokeratophore was a metallic probe preheated to a specific temperature range (90- 


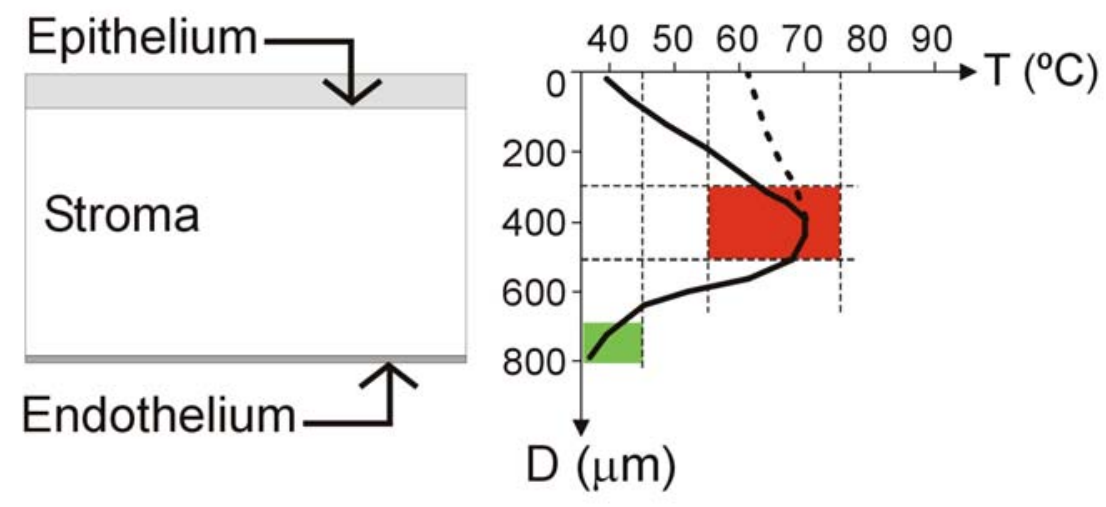

Fig. (1). Left: Schematic diagram of the cornea showing the anterior layer (epithelium), the posterior layer (endothelium), separated by the stroma. The aim of the thermokeratoplasty (TKP) procedure is to create safe localized heating in the central stroma. Right: Optimum (solid line) and sub optimum (dotted line) thermal profiles in the cornea for themokeratoplasty (TKP). TKP techniques are a complex challenge from the engineering point of view, due to requiring: 1) an extremely high spatial resolution (i.e. it is necessary to create very localized heating in a precise location of the central stroma -red zone-, thermally protecting the endothelium -green zone-, which is placed no more than $300 \mu \mathrm{m}$ distant from central stroma); and 2) a high resolution of the temperature reached at the target point (temperatures ranging from 58 to $76^{\circ} \mathrm{C}$ are required to shrink the collagen, and temperatures over $79^{\circ} \mathrm{C}$ are harmful). Since the epithelium is a layer with regeneration capability, it can stand heating during TKP(dotted line). However, in the optimum TKP technique the epithelium should be kept cool (solid line) and the heat focused on the central stroma.

$130^{\circ} \mathrm{C}$ ) and placed on the cornea surface, i.e. the thermal lesion was created by thermal conduction from the thermokeratophore towards the corneal stroma. Consequently, the maximum temperature was reached at the cornea surface $\left(\approx 75^{\circ} \mathrm{C}\right.$ ), while the central stroma remained at $\approx 45^{\circ} \mathrm{C}[11]$. In contrast, using the CSE, the maximum temperature in the cornea was reached at the central stroma $\left(\approx 70^{\circ} \mathrm{C}\right)$, both epithelium and endothelium remaining at a temperature lower than $50^{\circ} \mathrm{C}$. The applicator had a monopolar system, i.e. the $\mathrm{RF}$ currents were delivered between the CSE (active electrode) and a large dispersive electrode placed away from the CSE. This technique was first tested on excised pigs' eyes [11], later on an in vivo model with dogs' eyes (sacrificed within minutes of the treatment) [13], and finally some preliminary clinical trial were conducted on patients to treat keratoconus [14-16]. Although the CSE was very effective right away (the corneas were flattened), it was also a common experience that the flattening of these diseased corneas tended to diminish significantly within a few weeks. Unfortunately, the protocol did not allow performing re-treatments to determine whether longer term stability could be achieved (Doss, personal communication, Oct. 11, 1995). It is also important to point out that this technique has never been employed on relatively "normal" human corneas such as those found in astigmatism and hyperopic conditions (in contrast, in keratoconus the cornea has abnormal morphology and is also very thin).

The CSE technique was also proposed using a bipolar system (i.e. without using a dispersive electrode). Several arrangements with a variable number of electrodes were proposed [17] but never tested. The most novel idea of CSE was to cool the cornea surface during heating. In fact, the same idea was later employed in microwave thermal keratoplasty [5-7], and more recently, a system for surface cooling of the cornea during TKP has been patented, especially for electrical-induced techniques such as RF or microwave TKP [18].

\section{APPLICATORS WITHOUT SURFACE COOLING (DRY APPLICATORS)}

Prior to the development of the CSE, some experimental studies were conducted by using a two-electrode applicator for delivering RF currents (2 MHz) in a bipolar system (see Fig. 2A). The applicator, known as the localized current field ( $L C F$ ) device, was also developed at Los Alamos Scientific Laboratory [19]. It was employed in the veterinary field for hyperthermic therapy for neoplasia or degenerative corneal diseases [20,21]. A similar probe, i.e. based on a bipolar RF application, was later proposed for refractive surgery [22]. It consisted of a bipolar forceps which created thermal lesions in segments of perilimbal corneal tissue. To our knowledge it has never been tested.

Around 1993, Mendez and Mendez-Noble [23] proposed using a small surface application electrode to create small lesion spots (see Fig. 2C). The aim was the correction of hyperopia by producing steeping of the cornea by means of creating a series of eight spots of one millimeter in diameter distributed symmetrically around a seven millimeter diameter ring in the mid-periphery of the cornea. The electrode played the role of an active electrode, and a large-area disk was the dispersive electrode. In addition, a more complex applicator including up to eight electrodes was proposed to simultaneously create the circular lesion pattern [24]. Our group also conducted computational and experimental research to characterize the corneal lesions created by this kind of surface electrode application [25,26]. In a retrospective study of 166 cases Mendez and Mendez-Noble [23] found some cases of regression due to surface application. They considered that during the surface application, tear film or balanced salt solution on the cornea might cause a dissipation of the energy. In 1994 they therefore proposed the intrastromal application of RF energy by means of penetrating electrodes (see subsequent section). 


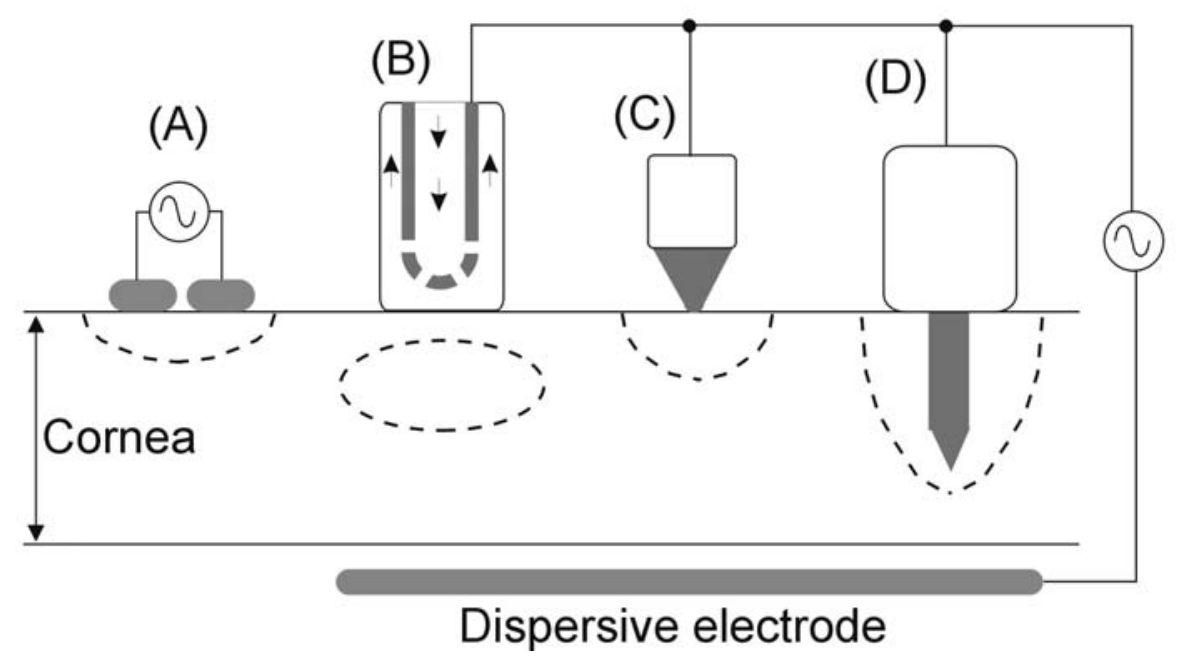

Fig. (2). RF electrodes and applicators for creating a lesion at a certain point in the cornea. A: A pair of electrodes cause a lesion by means of a bipolar application. B: The circulating saline electrode (CSE) works by delivering RF currents from the active electrode to a dispersive electrode while a flow of isotonic saline is infused over the cornea surface. C: A small surface electrode is placed on the cornea and RF currents are applied between this and a dispersive electrode. The lesion is hence confined to the cornea surface. D: An intrastromal electrode is a needle-shaped electrode which penetrates from the surface to the central stroma. The lesion has more depth than in the case of a surface electrode $(\mathrm{C})$.

Finally, we also conducted experimental research to assess the performance of a ring applicator for the rapid creation of a circular lesion pattern [27] (see Fig. 3A). The results suggested that the contact conditions between applicator and cornea surface should be balanced along the circular path in order to avoid zones with different lesion characteristics. In fact, it has been recognized that manual placement of the probe may involve human error, and hence the problem of controlling the contact between applicator and cornea has been broadly investigated in RF heating [28-30].

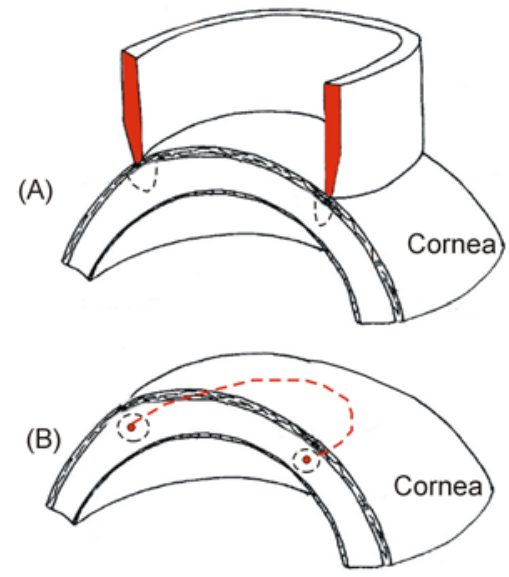

Fig. (3). Two types of RF electrodes for creating a circular lesion in the cornea (both use a monopolar system, i.e. the RF current circulates between the electrode and a dispersive electrode, which is not shown). A: A circular electrode placed on the cornea provides a circular lesion pattern. B: A small circular electrode is inserted into the central stroma (red dashed line), providing a toroidal lesion.

\section{INTRASTROMAL APPLICATORS}

The electrodes most frequently employed in clinical practice for RF heating of the cornea are the intrastromal elec- trodes. They were initially proposed by Mendez and Mendez-Noble in 1994 in order to improve the results obtained by surface application electrodes [23]. Briefly, the active electrode has a very fine tip that measures between 350 and $400 \mu \mathrm{m}$ in length and $\approx 100 \mu \mathrm{m}$ in diameter. It is inserted into the cornea and then the RF energy is directly applied into the stroma. Typical values are a frequency of $330-350 \mathrm{kHz}$ [3133 , and a power of $\approx 600 \mathrm{~mW}$ delivered for $\approx 600 \mathrm{~ms}$.

The electrical-thermal behavior of this kind of electrode has been extensively studied using computer modeling [3438]. The same kind of electrode has also been employed in other RF heating techniques such as ablation of cardiac arrhythmias [39]. It is known that RF power is mainly deposited at the electrode tip (see Fig. 4A). This behavior is especially advantageous for heating the cornea, since it allows direct heating of the central stroma. However, this electrode design offers additional advantages for cornea heating; since the electrode body is usually made of a conducting metal (e.g. stainless steel), the low thermal conductivity of this element compared to the thermal conductivity of the cornea facilitates the transmission of heat from the electrode tip to the anterior cornea (see Fig. 4B). As a result, a high thermal gradient appears between the electrode tip and endothelium, which provides thermal protection to the endothelium (see Fig. 4C).

We studied the effect of the thermal conductivity of the intrastromal electrode on the temperature profile in the cornea by means of theoretical modeling [40]. Fig. 5 shows the temperature profiles for intrastromal electrodes made from different materials, confirming the importance of the electrode body in diffusing the heat created at the electrode tip.

Finally, regarding intrastromal electrodes, it is interesting to note Silvestrini's proposal [41] for an RF applicator circular in shape (or semicircular or any other appropriate form) which is placed on the central stroma and inserted into the 


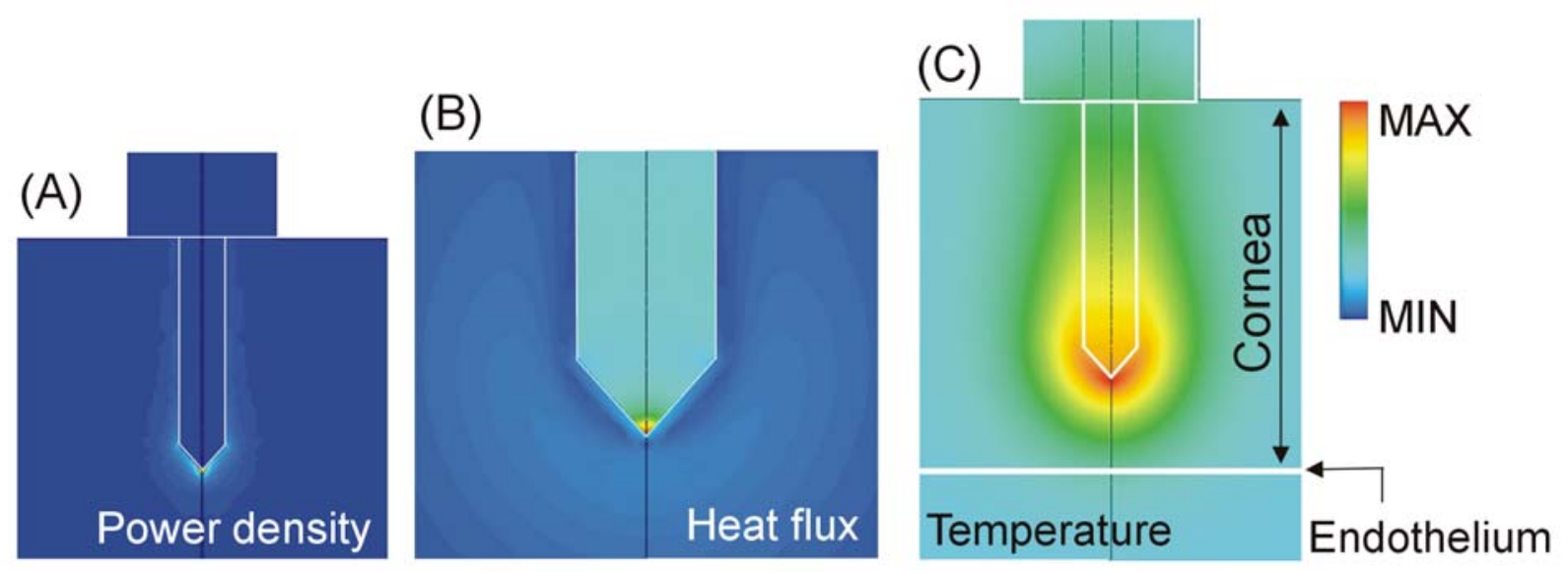

Fig. (4). Computer modeling of an intrastromal electrode. This kind of electrode has two important advantages: 1) the RF power is mainly deposited at the electrode tip (see Joule heat in A), and 2) the low thermal conductivity of the electrode metallic body facilitates the transmission of heat from the electrode tip to the anterior zone (see heat flux in B). Note that the maximum heat flux is located in the electrode, and in contrast, the corneal tissue shows a very low heat flux value. A high thermal gradient therefore appears between the electrode tip and endothelium, which provides thermal protection to the endothelium (see temperature in $\mathbf{C}$ ). Scales are normalized.

inner cornea through at least one access (see Fig. 3B). To our knowledge this device was never experimentally assessed.
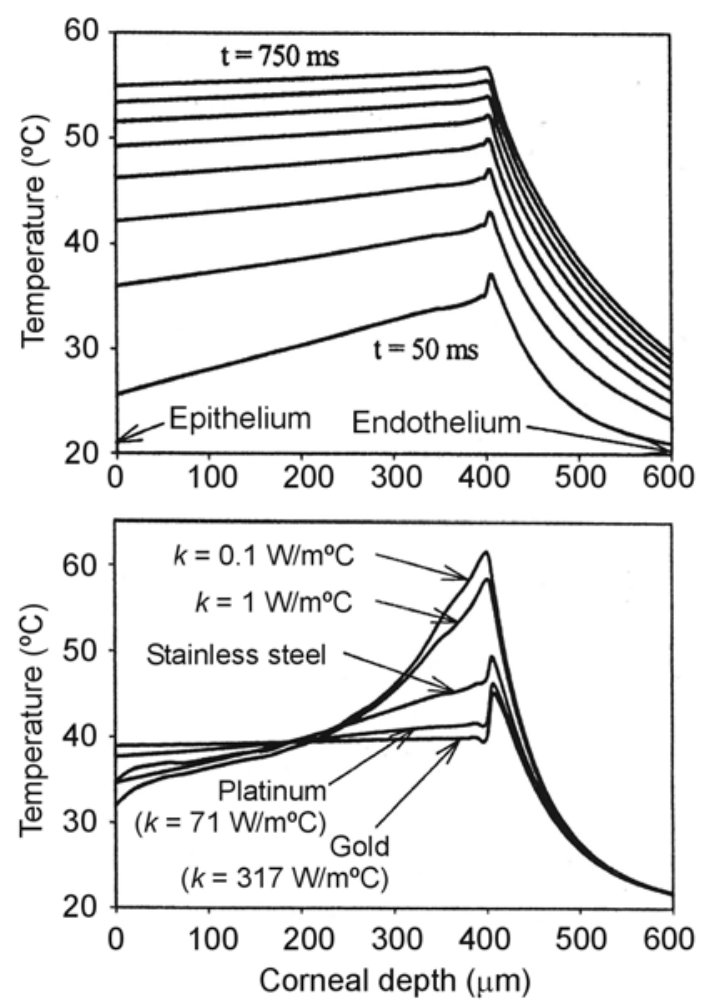

Fig. (5). Computer modeling of intrastromal electrodes. Top: Progress of the temperature profiles (assessed on the electrode axis) for an intrastromal electrode made of stainless steel (each plot represents a time step of $10 \mathrm{~ms}$ ). Bottom: Temperature profiles at $100 \mathrm{~ms}$ for intrastromal electrodes with different thermal conductivity values. Note that electrodes with low thermal conductivity can remove the heat generated at the electrode tip more efficiently. All the simulations were conducted by applying a constant voltage of $10 \mathrm{~V}$ and the electrode tip was located at a depth of $450 \mu \mathrm{m}$ in the cornea [41].

\section{COMPUTER MODELING STUDIES}

During the study and development of applicators for RF heating of the cornea, theoretical models and computer simulations have played an important role. This methodology is advantageous, being both fast and cheap, for assessing the electrical and thermal behavior of RF applicators [42]. For instance, computer modeling studies have been developed for surface applied monopolar electrodes, both for single [25] and circular lesion patterns [27]. Likewise, many computer modeling studies have been carried out on intrastromal electrodes, especially for those employed in Conductive Keratoplasty (CK) [34-38].

\section{CLINICAL RELEVANCE}

Even though numerous RF applicator designs for cornea heating have been proposed and experimentally tested, to date only the needle-shaped intrastromal applicators have achieved clinical success $[31,32,43]$. For instance, they were initially employed for the correction of low to moderate hyperopia [44], and to correct residual hyperopia after corneal surgery [45]. Subsequently, clinical trials were carried out on correcting hyperopic astigmatism [46] and presbyopia [47]. Corneal modeling of keratoconus has recently been conducted by means of this type of electrode [43].

From the clinical and manufacturing point of view, these electrodes were initially manufactured by Refractec (Irvine, CA, USA). This company currently develops and markets electrodes and an RF generator under the trade name of ViewPoint ${ }^{\circledR}$ CK System. The surgical procedure is known as Conductive Keratoplasty® (CK). In general, for the treatment of hyperopia, the lesion spots (which shrink corneal collagen in the treatment zone) are created following a full circular pattern (6, 7 and/or $8 \mathrm{~mm}$ diameters). This lesion pattern acts like a belt, tightening the peripheral region of the cornea so that the central cornea becomes slightly raised [48].

The Brazilian company Loktal Medical Electronics (Butantã, São Paulo, Brazil) has also developed similar elec- 
trodes (stainless steel tip of $90 \mu \mathrm{m}$ in diameter and $350 \mu \mathrm{m}$ in length) which are employed with an RF generator (Wavetronic Genius). To date, this equipment has been employed in a clinical study for treatment of advanced keratoconus [32]. In this case, the thermal spots were created in optical zones of 4.0 and $5.0 \mathrm{~mm}$ (the exact number of spots and their location were determined by the degree of corneal curvature) [32].

Both technologies (Refractec and Loktal) are based on delivering RF energy for a total time of $600 \mathrm{~ms}$ (typical value). During this period, the RF generator emits a train of pulses consisting of exponentially damped sinusoidal waves $(350 \mathrm{kHz})[31,32,38]$. The typical value of delivered power is $600 \mathrm{~mW}$, however other power values can be employed. On this topic, Choi et al [33] have studied in depth the effect of programmed power on impedance progress during heating.

\section{CONCLUSION}

This paper has reviewed the different applicators and electrodes employed to create localized heating in the cornea by means of the application of radiofrequency (RF) currents. Taking into consideration the extensive number of cornea heating techniques for purposes of refractive surgery proposed and tested to date (thermokeratophores, laser, microwave, ultrasound, radiofrequency), we believe that the problem has not yet been solved. Therefore, a great deal of research effort should be focused on finding the optimum RF applicator for cornea heating.

\section{ACKNOWLEDGMENTS}

This work was partially supported by the "Programa de Investigación y Desarrollo Tecnológico 2007 (Ref: IMIDTA/2007/586)" of the Institut de la Petita i Mitjana Indústria de la Comunitat Valenciana (IMPIVA-Generalitat Valenciana), and by the "Plan Nacional de Investigación Científica, Desarrollo e Innovación Tecnológica del Ministerio de Educación y Ciencia" of Spain (TEC 2005-04199/TCM). We would like to thank the $\mathrm{R}+\mathrm{D}+\mathrm{i}$ Linguistic Assistance Office at the Technical University of Valencia for their help in revising this paper.

\section{REFERENCES}

[1] A. Mendez-Gutierrez, "Review of thermokeratoplasty developments," in Conductive keratoplasty. A primer. J. R. Pinelli, S.E. Pascucci, Eds. Thorofare: SLACK, 2005, pp. 3-8.

[2] M.M. Ismail, J.J. Pérez-Santonja, J.L. Alió JL, "Correction of the hyperopia and hyperopic astigmatism by laser thermokeratoplasty," in Refractive Surgery: Current Techniques and Management. O.N. Serdarevic, Ed., New York:Igaku-Shoin, 1997, pp. 263-274.

[3] E.L. Shaw, A.R. Gasset, "Thermokeratoplasty (TKP) temperature profile,” Invest. Ophthalmol., vol. 13, pp. 181-186, 1974.

[4] Gasset AR, Kaufman HE, "Thermokeratoplasty in the treatment of keratoconus,” A. J. Ophthalmol., vol. 79, pp. 226-232, Feb. 1975.

[5] B.S. Trembly, N. Hashizume, K.L. Moodie, K.L. Cohen, N.K. Tripoli, P.J. Hoopes, "Microwave thermal keratoplasty for myopia: keratoscopic evaluation in porcine eyes," J. Refract. Surg., vol. 17(6), pp. 682-688, Nov-Dec. 2001.

[6] B.S. Trembly, R.H. Keates, "Combined microwave heating and surface cooling of the cornea," IEEE Trans. Biomed. Eng., vol. 38, pp. 85-91, Jan. 1991.

[7] B.S. Trembly, R.A. Crump, "Combined microwave heating and surface cooling of the cornea," U.S. Patent 4881 453, Nov. 21, 1989.

[8] A.R. Rutzen, C.W. Roberts, J. Driller, D. Gomez, B.C. Lucas, F.L. Lizzi, D.J. Coleman, "Production of corneal lesions using high- intensity focused ultrasound,” Cornea, vol. 9, pp. 324-330, Oct. 1990.

[9] D.B. Mark, R. Beuerman, "Intracorneal lesions produced with focused ultrasound,” Curr. Eye Res., vol. 2, pp. 323-326, 19821983.

[10] P.J. Klopotek, "Meted and apparatus for generating localized hyperthermia,” U.S. Patent 5230 334, Jul. 27, 1993.

[11] J.D. Doss, J.J. Rowsey, "A technique for the selective heating of corneal stroma," Contact Intraocul. Lens Med. J., vol. 6, pp. 13-17, Jan-Mar. 1980

[12] J.D. Doss, R.L. Hutson, “Corneal-chaping electrode,” U.S. Patent 4 326 529, Apr. 27, 1982.

[13] J.J. Rowsey JJ, J.R. Gaylor, R. Dahlstrom, J.D. Doss, "Los Alamos keratoplasty techniques," Contact Intraocul. Lens Med. J., vol. 6, pp. 1-12, Jan-Mar. 1980.

[14] J.J. Rowsey, J.D. Doss, "Preliminary report of Los Alamos Keratoplasty Techniques," Ophthalmol., vol. 88, pp. 755-760, Aug. 1981.

[15] P.J. McDonnell, J. Garbus, J.L. Romero, N.A. Rao, D.J. Schanzlin, "Electrosurgical keratoplasty. Clinicopathologic correlation," Arch. Ophthalmol., vol. 106, pp. 235-238, Feb. 1988.

[16] J.J. Rowsey, "Electrosurgical keratoplasty: update and retraction," Invest. Ophthalmol. Vis. Sci, vol. 28, p. 224, 1987.

[17] J.D. Doss, "Multipolar corneal-shaping electrode with flexible removable skirt," U.S. Patent 4381 007, Apr. 26, 1983.

[18] B.S. Trembly, "Thermokeratoplasty systems," U.S. Patent 7192 429, Mar. 20, 2007.

[19] J.D Doss, "Electrothermal treatment of cancer eye," Los Alamos Scientific Laboratory Mini-review 77-14. Aug. 1977.

[20] S.M. Neumann, R.A. Kainer, G.A. Severin, "Reaction of normal equine eyes to radio-frequency current-induced hyperthermia," $A$. J. Vet. Res., vol. 43, pp. 1938-1944, 1982.

[21] M.B. Glaze, M.A. Turk, "Effects of radiofrequency hyperthermia on the healthy canine cornea," A. J. Vet. Res., vol. 47, pp. 913-918, 1986.

[22] R.J. Fugo, “Method of ocular refractive surgery,” U.S. Patent 5423 815, Jun. 13, 1995.

[23] A. Mendez, A. Mendez Noble, "Conductive keratoplasty for the correction of hyperopia," in Surgery for hyperopia and presbyopia, N.A. Sher, Ed. Baltimore:Williams \& Wilkins, 1997, pp. 163-171.

[24] L. Hood, A.G. Mendez, "Method and apparatus for modifications of visual acuity by thermal means,” U.S. Patent 5533 999, Jul. 9, 1996.

[25] E.J. Berjano, J. Saiz, J.M. Ferrero, "Radio-frequency heating of the cornea: theoretical model and in vitro experiments," IEEE Trans. Biomed. Eng., vol. 49, pp. 196-205, Mar. 2002.

[26] M.E. Mulet, J.L. Alió, T.F. Salem, E.J. Berjano, "Corneal thermal lesions with radiofrequency currents for thermokeratoplasty," Invest. Ophthalmol. Vis. Sci., vol. 41, p. S919, 2000.

[27] E.J. Berjano, J. Saiz, J.L. Alio, J.M. Ferrero, "Ring electrode for radio-frequency heating of the cornea: modelling and in vitro experiments," Med. Biol. Eng. Comput., vol. 41, pp. 630-639, Nov. 2003.

[28] P.R. Goth, D. Panescu, S. Khalaj, "Thermokeratoplasty system with a guided probe tip," U.S. Patent 2005/0245949 A1, Nov. 3, 2005.

[29] M. Valle, S. Khalaj, L. Hood, D. Panescu, "Method and apparatus to automatically insert a probe into a cornea," U.S. Patent 2006/0184166 A1, Aug. 17, 2006.

[30] L. Hood, "Thermokeratoplasty system with a power supply that can determine a wet or dry cornea,” U.S. Patent 6,673,069 B1, Jan. 6, 2004.

[31] L.V. Paulino, E. Paulino, R.A. Barros, A.G. Salles, J.R. Rehder, "Corneal topographic alteration after radiofrequency application to an animal model," Arq. Bras. Oftalmol., vol. 68, pp. 415-456, JulAug. 2005.

[32] J.M. Lyra, F.C. Trindade, D. Lyra, A. Bezerra, "Outcomes of radiofrequency in advanced keratoconus,” J. Cataract. Refract. Surg., vol. 33, pp. 1288-1295, Jul. 2007.

[33] B. Choi, J. Kim, A.J. Welch, J.A. Pearce, "Dynamic impedance measurements during radio-frequency heating of cornea," IEEE Trans. Biomed. Eng., vol. 49, pp. 1610-1616, Dec. 2002.

[34] J.A. Pearce, C. Ikei, "Increasing corneal curvature by RF current: numerical model studies of governing physical processes," in Proc. SPIE, 2007, p. 6640. 
[35] J. Pearce, D. Panescu, S. Thomsen, "Simulation of diopter changes in radio frequency conductive keratoplasty in the cornea," in WIT Trans. Biomed. Health 2005, vol. 8, pp. 469-477.

[36] J.A. Pearce, D. Panescu, "Radio frequency conductive keratoplasty in the cornea: prediction of diopter changes in numerical models," in Proc. 26 th Annual Int. Conf. IEEE EMBS, 2004, pp. 5426-5429.

[37] J.A. Pearce, "Numerical model study of radio frequency conductive keratoplasty in the cornea for correction of hyperopia," in Proc. Second Joint EMBS/BMES Conf., 2002, pp. 2149-2150.

[38] E.J. Berjano, J.L. Alio, J. Saiz, "Modeling for radio-frequency conductive keratoplasty: implications for the maximum temperature reached in the cornea," Physiol. Meas., vol. 26, pp. 157-172, Jun. 2005.

[39] E.J. Woo, S. Tungjitkusolmun, H. Cao, J.Z. Tsai, J.G. Webster, V.R. Vorperian, J.A. Will, "A new catheter design using needle electrode for subendocardial RF ablation of ventricular muscles: finite element analysis and in vitro experiments," IEEE Trans. Biomed. Eng., vol. 47, pp. 23-31, Jan. 2000.

[40] E.J. Berjano, J. Saiz, J.M. Ferrero, J. Alió, "Effect of the termal conductivity of the intra-tissue active electrode during RF electrocoagulation,” in Proc. XVI Annual Congress Spanish Soc. Biomed. Eng., 1998, pp. 23-25.

[41] T.A. Silvestrini, "Electrosurgical procedure for treatment of the cornea,” U.S. Patent 5766 171, Jun. 16, 1998.
[42] E.J. Berjano, "Theoretical modeling for radiofrequency ablation: state-of-the-art and challenges for the future," Biomed. Eng. Online. 2006 18;5:24.

[43] J.L. Alio, P.J. Claramonte, A. Caliz, M.I. Ramzy, "Corneal modeling of keratoconus by conductive keratoplasty," J. Cataract. Refract. Surg., vol. 31, pp. 190-197, Jan. 2005.

[44] M.B McDonald, P.S. Hersh, E.E. Manche, R.K. Maloney, J. Davidorf, M. Sabry, "Conductive Keratoplasty United States Investigators Group. Conductive keratoplasty for the correction of low to moderate hyperopia: U.S. clinical trial 1-year results on 355 eyes," Ophthalmol., vol. 109, pp. 1978-1989, Nov. 2002.

[45] I.F. Comaish, M.A. Lawless. Conductive keratoplasty to correct residual hyperopia after corneal surgery. J. Cataract. Refract. Surg., vol. 29, pp. 202-206, Jan. 2003.

[46] I.G. Pallikaris, T.L. Naoumidi, N.I. Astyrakakis, "Conductive keratoplasty to correct hyperopic astigmatism," J. Refract. Surg., vol. 19, pp. 425-432, Jul-Aug. 2003.

[47] M.B. McDonald, D. Durrie, P. Asbell, R. Maloney, L. Nichamin, "Treatment of presbyopia with conductive keratoplasty: six-month results of the 1-year United States FDA clinical trial," Cornea, vol. 23, pp. 661-668, Oct. 2004.

[48] G.H. Strauss, "Mechanism of Conductive Keratoplasty," in Conductive keratoplasty. A primer. J. R. Pinelli, S.E. Pascucci, Eds. Thorofare:SLACK, 2005, pp. 11-19. 